\title{
Exceptional nest attendance and solo breeding attempt by an African White- backed Vulture.
}

\author{
Thomas Frederick Johnson \\ School of Biology, Faculty of Biological Sciences, University of Leeds, Leeds, LS2 9JT, UK \\ Correspondence: thomas.frederick.johnson@outlook.com
}

http://dx.doi.org/10.4314/vulnew.v74i1.5

\section{Introduction}

African White-backed Vultures Gyps africanus, like many bird species (Cockburn 2006), are monogamous and exhibit bi-parental care, where both birds share the incubation and feeding responsibility equally (Mundy et al. 1992). This is a common breeding strategy in birds because it enables one parent to incubate an egg whilst the other parent can forage, ensuring the egg is always attended and less vulnerable to predation (Cockburn 2006).

Bi-parental breeding is an effective reproductive strategy for White-backed Vultures because they exhibit a lengthy breeding period, incubating one egg for 56 days, before rearing a chick for 120-125 days (Mundy et al. 1992). After this, the fledgling will still be partially dependent on its parents for up to a further 5-6 months, in total, equating to nearly one year of incubation and feeding responsibility (Mundy et al. 1992). This level of breeding effort, whilst challenging for a pair of birds, would be almost impossible for a single bird. The extended absences required to forage efficiently would leave the nest unattended and the egg vulnerable to predation. Despite the difficulty inherent in a single bird attending the nest, here I present evidence of unusually long nest attendances and a solo egg incubation attempt by a White-backed Vulture.

\section{Methods}

White-backed Vulture breeding biology was studied at two colonies near Kimberley in the Northern Cape Province of South Africa. These colonies were located at Dronfield Nature Reserve $\left(28.63^{\circ} \mathrm{S}, 24.81^{\circ} \mathrm{E}\right)$ and Mokala National Park $\left(29.17^{\circ} \mathrm{S}, 24.32^{\circ} \mathrm{E}\right)$. To study breeding biology, camera traps (Prostalk (C) PC4000 5.0 megapixel, with a $60^{\circ}$ passive infrared sensor) were placed on 10 nesting trees, which recorded all movement on the nest (Figure 1). Nest attendance patterns were recorded as a time-series and described the duration of time spent incubating on the nest and time spent away from the nest. The specific plumage features for each bird at the different nests were detailed, so that each breeding bird on each nest could be uniquely identified. 


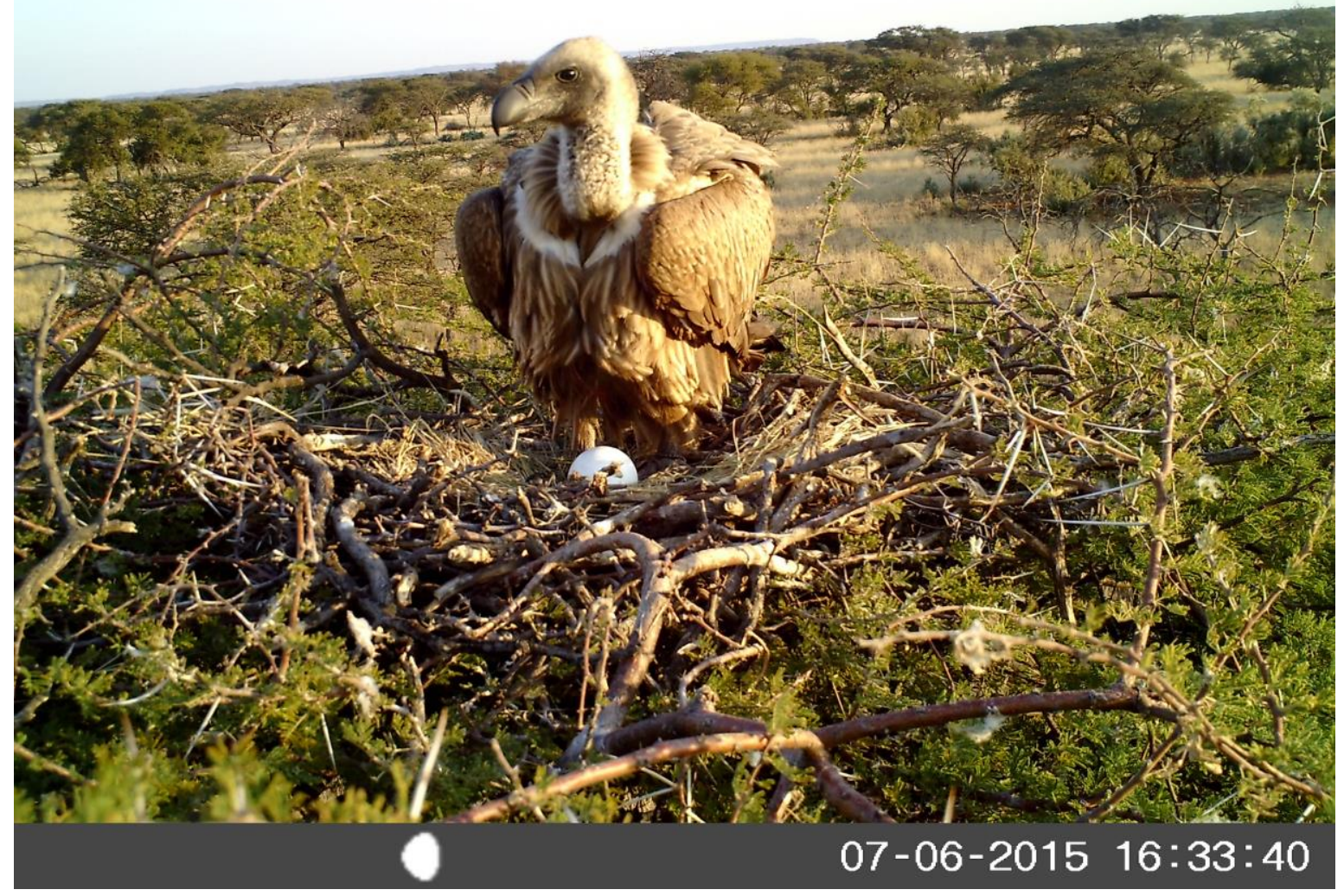

Figure 1: Camera trap image of an African White-backed Vulture Gyps africanus at its nest. Image shows the solo breeding bird.

\section{Results \& Discussion}

On one of the 10 studied nests, located in Mokala National Park, a lone breeding bird began incubating an egg without the assistance of a partner. Data collection began on this nest on 12 June 2015 and an egg was laid six days later. Within the pre-laying period no birds visited the nest. Data collection ended on this nest when the egg was abandoned on 18 July 2015, 30 days after the egg had been laid (Figure 2).

After the egg had been laid, the solo breeder was present at the nest for the majority (79\%) of the time. The mean incubation duration was $10 \mathrm{hrs} 40 \mathrm{~min}$ (standard error $[\mathrm{SE}]=115 \mathrm{~min}$ ), similar to that suggested by Mundy et al.
(1992), but considerably greater than the 5hrs 30min reported by Maphalala \& Monadjem (2017). The attendance patterns for this solo breeder showed large variation, ranging from $5 \mathrm{mins}$ to a maximum of 3 days, $18 \mathrm{hrs} 40 \mathrm{mins}$ on the nest. This extraordinary attendance period is much longer than the values reported in either Mundy et al. (1992) or Maphalala \& Monadjem (2017).

The solo breeder left the egg unattended on 55 occasions, ranging from $5 \mathrm{~min}$ to a maximum of $45 \mathrm{hrs} 5 \mathrm{~min}$ (mean $=2 \mathrm{hrs} 17 \mathrm{~min}, \mathrm{SE}=$ $52 \mathrm{~min}$ ). During these periods, the bird was only recorded returning from foraging (full crop/blood on face) once, having spent 35 minutes away from the nest. 


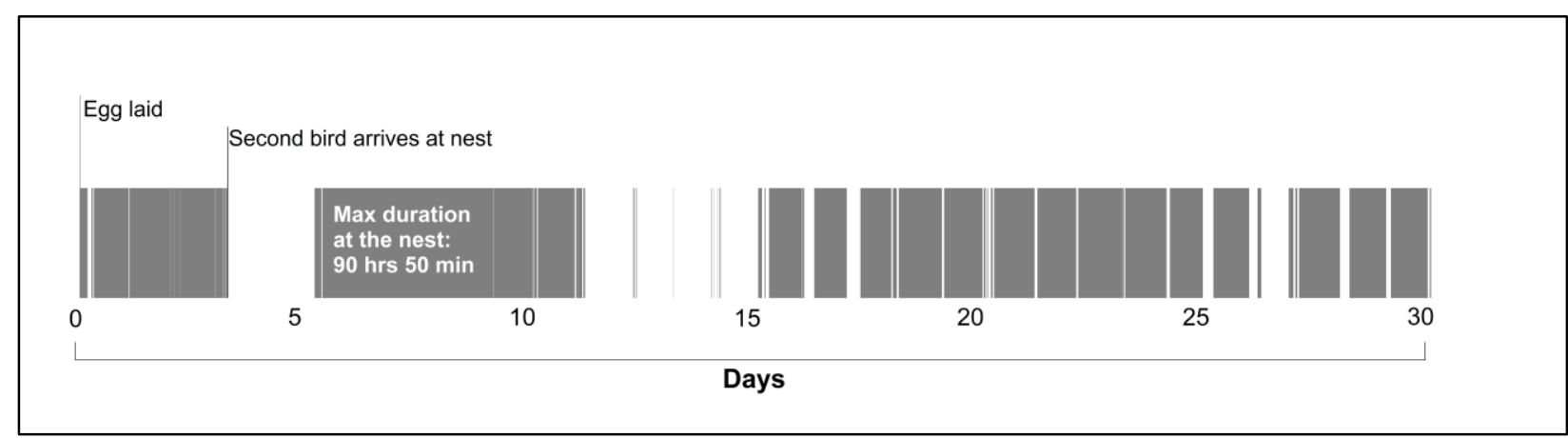

Figure 2: Changes in nest attendance of an African White-backed Vulture attempting to incubate an egg without a breeding partner, from days 0 - 30. Present at the nest (grey) and absent from the nest (whitegaps). The bird did not return to the nest after day 30 . The egg was laid on day 0 , and a second bird visited the nest on day 4 .

A second bird arrived on the nest four days after the egg had been laid, appearing to relieve the solo breeder from incubation duties. However, after the solo breeder left the nest, the second bird only remained at the nest for a further 5 minutes before departing and not returning, leaving the nest unattended for nearly two days. It is possible the second bird's arrival at the nest was traffic, described previously by Mundy et al. (1992), rather than incubation relief. This would explain why the second bird only stopped briefly at the nest. No other Whitebacked Vultures visited the nest.

It is unclear why the solo breeder did not return to the nest on day 30 ; it is possible the bird was becoming too dehydrated or malnourished from the prolonged incubation, so abandoned the nest to ensure its own survival. Alternatively, the solo breeder may have failed to return to the nest because it became injured or died. Regardless, hatching failure was possible, as the solo breeder did not incubate the egg for nearly two days (45hrs $5 \mathrm{~min}$ ) between days four and six, subjecting the embryo to cold $\left(<10^{\circ} \mathrm{C}\right)$ June overnight temperatures. Prolonged cold temperatures can cause hypothermia in eggs, reducing hatching success (Webb, 1987).

The solo breeder was present at the nest for considerably longer than would be required if it were sharing incubation duties with a partner. These exceptional incubation stints have not been reported for White-backed Vultures previously and any evidence of this behaviour being widespread within the population remains to be found. However, it is relevant to note that, as is the case in this study, it is unlikely a solo breeding White-backed Vulture could sustain sufficiently long incubation durations to incubate an egg and then rear a chick successfully. This is important, as solo incubation and chick rearing is thus unlikely to be an adaptive behaviour, unlike cases where monogamous bi-parental breeders shift to polygamous systems to increase their reproductive output (Heg \& van Treuren, 1998).

Determining the prevalence of lonebreeding in White-backed Vultures will be challenging as the birds are sexually monomorphic. However, breeding surveys should place extra emphasis on monitoring tagged birds, where individuals could be uniquely identified without the need for camera traps.

\section{Acknowledgments}

Thanks to Hawk Conservancy Trust, Puy du Fou, DeBeers and SANParks for funding and access to field sites. Particular thanks to Campbell Murn, Angus Anthony, Beryl Wilson, Ronelle Visagie, Jarryd Elan-Puttick, Charles Hall and Corné Anderson for help of various sorts. 


\section{References}

Cockburn, A. 2006. Prevalence of different modes of parental care in birds. Proceedings of the Royal Society, London B 273: 1375-1383.

Heg, D. \& van Treuren, R. 1998. Female-female cooperation in polygynous oystercatchers. Nature 391(6668): 687-691.

Maphalala, M.I. \& Monadjem, A. 2017. White-backed Vulture Gyps africanus parental care and chick growth rates assessed by camera traps and morphometric measurements. Ostrich 88: 123-129.

Mundy, P., Butchart, D., Ledger, J. \& Piper, S. 1992. The vultures of Africa. Academic Press, London.

Webb, D.R. 1987. Thermal tolerance of avian embryos: a review. Condor 89: 874-898.

******* 